\title{
ESPLENDOR Y OCASO DE LA SOSTENIBILIDAD
}

\author{
José Fariña Tojo (Dr. Arquitecto - Catedrático DUyOT)
}

En el año 1987 una comisión de la ONU coordinada por la primera ministra noruega Gro Harlem Brundtland elabora un informe que, en principio, llevaba el nombre de Nuestro Futuro Común. Este informe (también llamado informe Brundtland) pienso que, probablemente sea el texto más citado cuando se habla de sostenibilidad. $Y$, en concreto, el párrafo que se incluye en el capítulo 2 titulado "Hacia un desarrollo duradero" que dice: "El desarrollo duradero es el desarrollo que satisface las necesidades de la generación presente sin comprometer la capacidad de las generaciones futuras para satisfacer sus propias necesidades." Pero también me temo que es el texto menos leído en su totalidad a pesar de que todos lo citan (si exceptuamos El Quijote, claro, también muy citado pero escasamente leído en su totalidad).

Y es que en ese texto se decían cosas muy duras bajo un manto ciertamente optimista. Se podría resumir su espíritu diciendo que la salud del planeta está muy mal pero, entre todos, conseguiremos que esté muy bien. Lo que no se decía es cómo conseguirlo. En el punto 25 de la Introducción (An Overview by the World Commission on Environment and Development) se podía leer que: "Muchos de los actuales esfuerzos por conservar y mantener el progreso humano, satisfacer las necesidades humanas y realizar las ambiciones humanas son simplemente insostenibles - tanto en las naciones ricas como en las pobres -. Retiran en demasiada cantidad y con demasiada rapidez de las cuentas ya en exceso explotadas de los recursos del medio ambiente, para que sea posible continuar en el futuro sin caer en la bancarrota. Es posible que aparezcan beneficios en los balances de nuestra generación, pero nuestros hijos heredarán las pérdidas. Estamos tomando prestado capital del medio ambiente de las futuras generaciones sin intención ni perspectivas de reembolso. Es posible que nos condenen por nuestra manera de actuar dispendiosa, pero no podrán cobrar la deuda que estamos contrayendo con ellos. Actuamos como si eso no importara: las generaciones futuras no votan, no tienen poder político ni financiero, no pueden oponerse a nuestras decisiones".

Desde entonces han transcurrido casi treinta años. Casi treinta años en los cuales han pasado muchas cosas, pero pocas avalan el optimismo que tiñe el informe. El punto 29 de la Introducción decía que "el desarrollo duradero a nivel mundial exige que quienes son más ricos adopten medidas acordes con medios que respeten la ecología del planeta, en el uso de la energía, por ejemplo. Además, la rapidez del crecimiento de la población puede intensificar la presión sobre los recursos y retardar el progreso del nivel de vida. Se puede, pues, proseguir el desarrollo duradero únicamente si el tamaño y el crecimiento de la población están acordes con las cambiantes posibilidades de producción del ecosistema". Nada de esto se ha tenido en cuenta. Los países más poderosos, los grupos de presión que ostentan el poder de forma directa o indirecta han actuado de forma que, no sólo han tenido en cuenta a las generaciones futuras, sino que la distancia entre ricos y pobres (territorios, clases sociales, grupos) se ha ido incrementando en lugar de disminuir y el "debe" se ha ido incrementando de forma progresiva. 
Y esto se refleja como una metáfora en la propia evolución del término. Diez años después de publicarse el informe Brundtland José Manuel Naredo publica un artículo que puede leerse en $\mathrm{CF}+\mathrm{S}$ titulado "Sobre el origen, el uso y el contenido del término sostenible" cuya lectura aconsejo a todos aquellos que quieran entender como el sistema es capaz de asimilar, deglutir y convertir en otra cosa cualquier concepto que le resulte incómodo. Explica José Manuel como se vetó el término ecodesarrollo (ya antes de publicarse Nuestro Futuro Común) por sus implicaciones ecológicas, y luego se adaptó la expresión "desarrollo sostenible" como una especie de tierra de nadie entre desarrollistas y ambientalistas. Y se hizo así debido a su ambigüedad que permitía continuar con el sistema económico tradicional de crecimiento sin límites siempre que se atendiera de forma cosmética a la sostenibilidad de un sistema que, por supuesto, se sobreentendía no sostenible sin crecimiento económico. La expresión hizo fortuna y el término "desarrollo sostenible" pasó del acervo de la economía a la política.

Este paso se hizo ignorando, de una forma descarada, la sostenibilidad global y centrándose en la local. De forma que el "desarrollo sostenible" se entendió como aquel que miraba exclusivamente la posibilidad de mantener el desarrollo de "mi trocito" (territorial, empresarial, social) presuponiendo que todo el capital natural que yo consumiera "alguien" en "algún sitio" iba a dejar de consumirlo. Fue la época dorada de la planificación estratégica que trataba de conseguir la mayor cuota de riqueza, empleos y desarrollo, en un mundo competitivo y limitado. Por supuesto a costa de otros. Pronto se vio que esto era "insostenible" cuando determinados "trocitos" (por ejemplo, Brasil) se negaron a dejar de consumir su cuota para que otros se beneficiaran. Se empezó entonces a hablar de "sostenibilidad" como concepto más ecológico y global ya que era la única forma de que los que estaban por debajo de la media de consumo de planeta siguieran como estaban (o empeoraran) para que los que consumían por encima pudieran seguir haciéndolo. Ahora la sostenibilidad debía de ser global siempre y cuando los países ricos siguieran consumiendo como antes y los más pobres también. Todos los territorios, todos los grupos, todas las clases sociales, deberían entrar en la contabilidad global mundial y los consumos se equilibraban mediante unas limosnas en forma de cuotas.

Se empezó a hablar (todavía se habla) de sostenibilidad fuerte y débil. Como si fuera posible otro tipo de sostenibilidad más que la derivada de una justicia intergeneracional, interterritorial y social, que es la que está en el fondo del concepto. Así que todo empezó a ser "sostenible" (eso sí, "débilmente sostenible"). Se hacían juguetes sostenibles, leyes sostenibles, hasta los equipos de fútbol eran sostenibles (no es un eufemismo). Pero lo peor de todo es que los políticos adoptaron el adjetivo sostenible como una muletilla aplicable a cualquier cosa. Sobre todo a los temas ambientales locales cuya solución pasaba por desplazar el problema a otros sitios sin poder económico, político o militar. Así muchos países africanos empezaron a llenarse de chatarra tecnológica procedente de los países más ricos que se desprendían de ella a muy bajo costo y resolvían su problema local en pro de la sostenibilidad de Berlín, Oslo, Madrid o Nueva York. De tal forma que los políticos proponían resolver el problema de la contaminación de "su" ciudad utilizando, por ejemplo, coches eléctricos. Dado que la electricidad se produce de forma mayoritaria en centrales térmicas lo que se hacía era desplazar el problema de Madrid a Os Pontes. Eso sí, los 
madrileños podían respirar tranquilos y seguir consumiendo energía y contribuyendo al cambio climático, aunque no se enteraran de nada.

De forma que el paso del "desarrollo sostenible" (ya con muy mala prensa) a la "sostenibilidad" se produjo casi sin traumas. Pero la palabra se llenó de connotaciones espurias y la consiguiente polisemia tanto del sustantivo como del adjetivo la fue devaluando de forma progresiva. En el momento actual ya empieza a existir un cierto reparo a utilizarla incluso entre los políticos. Personalmente ya hace tiempo que he decidido no utilizarla en la medida de lo posible. O si lo hago tengo que dedicar un buen rato a explicar cuál es el sentido que le doy que no es más que el reflejo de un compromiso con la justicia intergeneracional, interterritorial y social. Después de unos comienzos prometedores en los que parecía que todos eran solidarios, comprometidos y ecológicos las cosas se fueron degradando.

En el año 1988, sólo un año después de publicarse Nuestro Futuro Común, se crea el Grupo Intergubernamental sobre Cambio Climático (GIEC-IPCC) con el sano propósito de seguir de forma científica el calentamiento climático. En 1992 se celebra la Cumbre de la Tierra en Río de Janeiro en la cual 173 jefes de estado adoptan el programa "Acción 21" que tendrá una enorme importancia en los momentos de esplendor de la "sostenibilidad" como praxis a favor de la justicia. Tres años después se celebra en Copenhague la cumbre mundial sobre desarrollo social en la que 128 jefes de estado y gobierno se plantean abordar de forma prioritaria la pobreza, el desempleo y la desintegración social. En la Cumbre de las ciudades de Estambul de 1996 los estados abordan el tema de la vivienda digna y unas ciudades respetuosas con el medio ambiente. Ya el lobo empezaba a sacar su patita en forma de un entendimiento del medio ambiente como "nuestro medio ambiente" pero, en general, el optimismo y la ilusión eran todavía generalizados. Es optimismo sigue presente en la Cumbre del Milenio celebrada en Nueva York en el año 2000, cumbre en la que se fijas los llamados "objetivos del milenio". Estamos en los momentos de esplendor.

Pero a partir de este momento las cosas empiezan a ponerse cuesta arriba: la cumbre del 2002 celebrada en Johannesburgo es el inicio del sálvese quien pueda. Todavía de forma tímida pero al lobo ya se le veía, no sólo la patita, sino también el hocico. Es la cumbre que podríamos llamar de los partenariados porque ya las empresas empiezan a ver las posibilidades de negocio. En el 2005 entra en vigor el protocolo de Kioto firmado con gran entusiasmo en 1997 (en la época esplendorosa de la sostenibilidad) y luego ratificado en 2010 por 168 estados para conseguir llegar a un compromiso por parte de un conjunto de países que representaran el $55 \%$ de las emisiones de gases con efecto invernadero. Es bien sabido que, por ejemplo, USA, el principal emisor de este tipo de gases no lo ratificó. A pesar del incumplimiento generalizado se propuso una prórroga que abarca desde el 2013 hasta el 2020 pero esta prórroga ni tan siquiera ha sido firmada por países tan importantes como Rusia, Estados Unidos o Japón. El último fiasco ha sido la cumbre de Rio+20 celebrada en el 2012 en la que los países no han conseguido llegar a ningún acuerdo operativo. De la última cumbre del clima auspiciada por la ONU mejor no hablar y eso que a finales de 2014 Estados Unidos y China han firmado un acuerdo para controlarse un poco.

El problema es que los países más ricos han empezado a comprobar que lo que decían algunos "catastrofistas" hace unos años parece que era cierto. Que estamos consumiendo más que lo que la biocapacidad de la Tierra es capaz de producir. Y que 
el planeta es una tarta limitada de la que tienen que comer 7000 millones de seres humanos. Y que si los 6000 millones que ahora consumen menos consumieran lo que les corresponde, los 1000 millones que consumen más tendrían que disminuirlo. El cambio tremendo que se ha producido desde mediados de los años ochenta es que, cuando en cualquier parte del planeta se superaba el nivel de consumo de las regiones urbanas o de los países no había problema, se expandían estos ámbitos ya que todavía teníamos suficiente planeta para hacerlo. Esta expansión se podía conseguir en forma de guerras, acuerdos comerciales o conquistas financieras. Pero eso se ha terminado. La huella ecológica producida por el consumo humano ha superado la superficie de la Tierra. Y lo que es peor, estamos consumiendo las reservas a las que, además, se les ve el fin.

La llamada sostenibilidad ya solo es posible de dos formas. O bien, de acuerdo con la justicia repartiendo la tarta. O bien, si queremos que los que más tienen tengan todavía más, quitándoselo a los que menos tienen. El problema es que un sistema económico basado en el crecimiento no puede funcionar si esa pequeña parte que lo domina no consume cada vez más. Los que me conocen ya saben lo que voy a decir a continuación. El sistema tiene una gran resiliencia en sí mismo. Ha dado pruebas a lo largo de la historia humana de tener la suficiente capacidad como para mantenerse a pesar de las mayores dificultades. No tengo ninguna duda de que el sistema encontrará por sí mismo la forma de perpetuarse. Es decir, no soy un catastrofista que piensa que todo se va a hundir y que la especie humana va a desaparecer de la faz de la Tierra. De lo que tampoco tengo dudas es de que, o controlamos el proceso, o mucha gente va a sufrir mucho. Mejor dicho, los que ya ahora sufren van a sufrir todavía más. Y muchos de los que se creían a salvo de tales sufrimientos (las llamadas clases medias) van a entrar en este grupo. La sostenibilidad entrará, por tanto, en una nueva fase.

Nota: he preferido no incluir citas ni bibliografía, excepto las directas que aparecen en el texto. Todas las referencias son de notorio conocimiento, y no harían más que enturbiar la lectura del artículo y la construcción del discurso ya de por sí bastante complejo. 